\title{
HISTÓRIA SOCIAL DA INFÂNCIA NO BRASIL: PRÁTICAS ESCOLARES DO JARDIM DE INFÂNCIA MODELO DE NATAL - RN (1953 - 1965)
}

\author{
J. M. NASCIMENTO \\ Instituto Federal de Educação, Ciência e Tecnologia do Rio Grande do Norte \\ mateus.nascimento@ifrn.edu.br
}

Artigo submetido em julho/2016 e aceito em julho/2016

DOI: $10.15628 /$ holos.2016.4854

\section{RESUMO}

O artigo trata das práticas escolares do Jardim de Infância Modelo de Natal, Rio Grande do Norte, como instituição de educativa de relevância para história social da infância no Brasil, durante os anos 1950 e 1960. Pesquisa historiográfica realizada a partir de documentos dispostos no Instituto Histórico e Geográfico do Rio Grande do Norte. O estudo objetiva evidenciar a história dos jardins de infância no âmbito da história das instituições escolares, destacando elementos que integram a cultura escolar desses estabelecimentos de ensino, que funcionaram como importante campo de aplicação pedagógica das escolas normais e institutos de educação.

PALAVRAS-CHAVE: História da Educação, História Social da Infância, Jardim de Infância Modelo

\section{SOCIAL HISTORY OF CHILDREN IN BRAZIL: SCHOOL PRACTICES OF GARDEN CHILDHOOD MODEL OF NATAL - RN (1953 - 1965)}

\begin{abstract}
The article deals with the pedagogical practices of Garden Childhood Model, Rio Grande do Norte, as relevant educational institution for social history of childhood in Brazil during the 1950s and 1960s. Historiographical survey conducted from documents preserved at the Institute History and Geography of Rio Grande do
\end{abstract}

Norte.The study aims to highlight the history of kindergartens within the history of school institutions, highlighting elements that are part of the school culture of these schools, which functioned as an important pedagogical scope of the normal schools and educational institutions.

KEYWORDS: Education History, Social History of Childhood, Childhood Model Garden 


\section{INTRODUÇÃO}

Abordar sobre as práticas escolares instituídas por um Jardim de Infância, em Natal, no Rio Grande do Norte, significa rememorar parte importante da história social da infância do nordeste do Brasil, primordialmente, tratar acerca da história dos jardins de infância, instituições de ensino que funcionaram, também, como campo de aplicação das escolas normais, contribuindo com a formação de professoras para o ensino primário.

Nosso objetivo, neste trabalho, é focar no conjunto de práticas escolares que fomentaram um tipo de cultura escolar peculiar aos jardins de infância modelo, este criado como espaço de institucionalização da infância no que ficou conhecida como proposta de educação moderna ou tempos de civilidade para a criança, aquela que passou a ser tratada como "alumnus" ou "alumnié", termo de origem latina que significa "aquele que está disposto para aprender, que caminha na direção da luz", proposição proveniente da tradição grega que compreende a aquisição do conhecimento como ato de iluminação da alma, semelhante ao fenômeno explicitado por Platão por meio do Mito da Caverna, narrativa presente no Livro 7 da obra A República, escrito entre os anos 385 e 380 a.C..

A criança frequentadora do jardim de infância passou a participar de atividades planejadas e, por isso, a compor o processo de pedagogização do infante. Nesse sentido, as atividades direcionadas às crianças passaram a ser planejadas, pensadas para elas, com um fim de formação da pessoa humana. Nesse contexto, nada é fortuito, nunca gratuito, as atitudes passam a ser regidas por objetivos, metas e justificativas.

Desse modo, a constituição de uma cultura escolar se baseia na articulação de práticas escolares que exigem dos sujeitos envolvimento e compromisso. No caso do ambiente do jardim de infância, requereu um processo de assimilação e até adaptação à rotina instituída com seus horários, espaços, materiais e comportamentos convencionados socialmente como adequados. No interior dessas instituições passaram a ser cultivadas práticas de conformação social dos sujeitos aos modelos apresentados pela sociedade dita moderna.

Nesta oportunidade, aqui refletimos sobre a categorização e as finalidades das práticas escolares vivenciadas no interior da cultura escolar do Jardim de Infância Modelo de Natal, instituição situada na Praça Pedro Velho, no Bairro de Petrópolis, Natal, RN. O estabelecimento era integrante do denominado Instituto de Educação, complexo dedicado ao fortalecimento do ensino primário e a formação de normalistas no Brasil, projeto educacional idealizado pelos intelectuais Fernando de Azevedo, Anísio Teixeira e Lourenço Filho, durante os anos 1940 e 1950.

Pelo que prescrevia a Lei Orgânica do Ensino Normal, Decreto-Lei no 8.530, de 02 de janeiro de 1946, que regulamentava o Ensino Normal nos Institutos de Educação em todo o território nacional, o Instituto de Educação consistia num complexo composto pelos estabelecimentos: jardim de infância, grupo escolar, curso ginasial, curso de formação de professores primários, curso de especialização do magistério primário e de habilitação de administração escolar do grau primário.

O Instituto de Educação é tratado por Martins (2000, p. 04) como "casa de aculturação" porque objetivava "[...] a formação de um novo professor primário que unisse espírito democrático 
e formação científica. Esse era o desafio que o corpo docente do Instituto de Educação teria a partir da metade da década de 1940. [...]". Nesse sentido, a instituição ajudou a firmar um novo modelo de ser criança na sociedade brasileira, aquela escolarizada desde a primeira infância como pressuposto de civilidade, urbanização e modernização das práticas escolares.

Especificamente, no cotidiano do Jardim de Infância Modelo de Natal, as práticas escolares se materializavam pela vivencia de atividades que possuíam finalidades diferentes. Com base nos documentos icnográficos dispostos nos arquivos do Instituto de Educação Superior Presidente Kennedy (IESP), as atividades são classificadas por Mendes (2015) como sendo de formação intelectual, moral e física. Tríade esta, que sustentou o projeto pedagógico da instituição pesquisada, com o compromisso de acompanhar o desenvolvimento cognitivo, cultural, cívico e corporal dos sujeitos, desde a mais tenra idade.

O presente artigo é resultado de um estudo de cunho bibliográfico e etnográfico de fontes dispostas em arquivos públicos de instituições de formação de professores como o IESP e o acervo documental do Instituto Histórico e Geográfico do Rio Grande do Norte. É opção nossa considerar o arquivo como local por excelência para o "garimpo das fontes", buscando preservar a atitude primordial do pesquisador em história da educação, que interage com os documentostestemunhos-monumentos dispostos nas caixas, estantes e prateleiras.

Nos dispomos a realizar uma análise historiográfica sob a ótica de Le Goff (1994) como sendo mais uma versão contada sob a interpretação particular de quem narra e escreve, de modo que se inclui aspectos de uma realidade, mas também das representações com seus elementos simbólicos, na busca por uma semântica histórica. Esse método de fazer história permite múltiplas interpretações sobre um mesmo fato ou fenômeno, a partir do diálogo/cruzamento das fontes dispostas nos arquivos. O ofício está em interagir criticamente, sempre desconfiando, procurando sentido para as narrativas, explorando as intencionalidades e até mesmo o não dito anunciado por Certeau (1982) quando admitiu a condição da relatividade histórica.

\section{SOBRE CULTURA ESCOLAR E OS JARDINS DE INFÂNCIA NO BRASIL}

Os jardins de infância no Brasil instituíram um modo específico de cuidar da infância no interior de instituições denominadas de asilos, internatos, patronatos, creches e pré-escolas, sendo eficazes na divulgação de um modo próprio de contribuir com a formação da criança na faixa de 0 a 6 anos de idade. Tais instituições de ensino foram responsáveis tanto pela construção e manutenção de mentalidades sobre a infância como implantação de uma cultura escolar específica.

Refletir sobre cultura escolar significa considerar as práticas escolares desenvolvidas no cotidiano dessas instituições de assistência à criança; entender o perfil social desses sujeitos envolvidos; analisar os saberes e conhecimentos (re)produzidos nesse espaço escolar; inclusive, reconhecer o espaço da educação infantil como fase da vida humana, que se constitui oportunidade para a formação social do indivíduo. Julia (2001) entende a cultura escolar como objeto histórico que pode se organizar de diversas formas pelas práticas escolares, de maneira singular e original, conforme a realidade de cada instituição de ensino e cultura local ou da região. Desse modo a cultura escolar é definida como um conjunto de normas que ordenam 
conhecimentos e condutas no processo de formação de sujeitos escolarizados, contextualizados social e historicamente.

No seio da sociedade moderna, a escola tem por finalidade a conformação das novas gerações e pouco contribui para emancipação real desses sujeitos. Há um modelo de sociedade, para qual se (re)produz um conjunto de valores e conceitos a inculcar com finalidades acertadas e metas objetivas. As práticas escolares são historicamente formuladas, por isso apresentam uma intencionalidade social e cultural que reflete nos modos de pensar e agir dos sujeitos envolvidos. A instituição escola, no modelo que temos hoje, apresenta-se como invenção moderna e que admite a organização de um currículo com suas disciplinas escolares, uma rotina com seus horários e atividades a serem cumpridos e a organização de espaços específicos para atender à um conjunto de finalidades.

No Brasil, o processo crescente da industrialização e o protagonismo da mulher no mundo do trabalho fizeram com que a guarda da infância fosse assumida por instituições assistencialistas e caritativas, denominadas de creches, asilos, orfanatos e patronatos, com a finalidade de atender a uma demanda social de operárias, mulheres-mães-trabalhadoras, que necessitavam cumprir suas jornadas de trabalho e eram desprovidas de lugar apropriado para deixar a prole. O Estado se omitia da responsabilidade e, frequentemente, as instituições religiosas, filantrópicas e privadas assumiram a difícil tarefa por décadas em nosso país. Essas instituições, segundo Kuhlmann Júnior (2000, p. 8), se fundamentavam numa

[...] concepção da assistência científica, formulada no início do século XX, em consonância com as propostas das instituições de educação popular difundidas nos congressos e nas exposições internacionais, já previa que o atendimento da pobreza não deveria ser feito com grandes investimentos. A educação assistencialista promovia uma pedagogia da submissão, que pretendia preparar os pobres para aceitar a exploração social. O Estado não deveria gerir diretamente as instituições, repassando recursos para as entidades.

As creches foram as primeiras instituições de amparo que se preocuparam com o bem estar social da infância pobre brasileira. Amplamente criticada por se constituírem "depósito de crianças", mas que, historicamente, prestou significativo trabalho às classes populares das periferias dos grandes centros urbanos. Somente a partir dos anos 1960 é que o estado assume as causas das creches como política pública, atendendo a uma demanda social. Momento em que passa de subsidiador para criador e mantenedor, promovendo uma rede de assistência a infância pobre, aquela classificada como carente, desvalida e até delinquente.

A proposta alemã de Froebel do jardim de infância como espaço apropriado para acolher a criança diferia da funcionalidade social das creches brasileiras. O contexto histórico e cultural de criação dos "Kindergardens", em 1837, na Alemanha, tem por referência os princípios de uma pedagogia moderna e atendimento a uma infância proveniente de famílias abastadas que desejavam investir, desde cedo, na educação de seus filhos. O jardim de infância seria o primeiro espaço de formação ordenada/planejada/intencional desses sujeitos, que se preparavam para ingressar na escola formal. Dessa lógica advém o termo pré-escolar, que significa o período dedicado à preparação, iniciação à trajetória estudantil.

Segundo Cardoso Filho (2006, p. 1684), Froebel trata de uma prática pedagógica que a sistematiza na obra 'A educação do homem', publicada em 1826 
[...] na qual expõe seu pensamento educacional, o desenvolvimento das crianças nos anos iniciais do ensino primário, e sua concepção da instrução escolar. Nesta obra, seguindo-se a uma extensa parte introdutória de caráter filosófico, os capítulos destinados à prática pedagógica tratam de questões gerais, como a importância do ensino das artes, da religião, matemáticas, língua, e da natureza. Nos capítulos finais, mais detalhados, inclusive descrevendo modelos e exemplos, são abordados tópicos como o conhecimento, estima e a perfeição do corpo; a observação do mundo exterior; a utilidade do emprego da poesia e do canto; exercícios de oralidade, escritura e leitura; conhecimento dos numerais e das formas; o jogo; e da utilidade das pequenas viagens e longos passeios.

Nesse sentido, o termo "jardim de infância" abriga em si o sentido da criação de uma instituição de ensino destinada a educação formal da criança pequena. A atribuição desse novo equipamento social agregaria a dimensão educar a atividade de cuidar, esta essencialmente realizada pelas creches e orfanatos. Os jardins de infância formalizam uma forma científica de tratar a criança na faixa etária de 0 a 6 anos, pelas contribuições advindas dos campos da psicologia do desenvolvimento e da aprendizagem e do método intuitivo. Conjunto de conhecimentos que fundamentam o funcionamento de uma escola ativa, pautada num contexto em que as aprendizagens ocorrem a partir das experiências, de maneira sensorial, pela interação com materiais concretos, o meio ambiente e as pessoas.

Um dos primeiros jardins de infância implantados no Brasil foi criado no estado do Paraná, em 1869, pela professora pernambucana Emília Faria de Albuquerque Erichsen (CARDOSO FILHO, 2006, p. 1683) que se dedicou a atender, pedagogicamente, crianças de 4 a 6 anos de idade em sua própria residência, na rua das Tropas, na cidade de Castro, sob as diretrizes da didática froebeliana. Tratava-se de uma experiência pessoal, não oficial, mas reconhecida pela história da educação infantil como uma iniciativa memorável.

O ano de 1875 foi marcado pela inauguração do Colégio Menezes Vieira, situado à rua dos Inválidos, 26, no Rio de Janeiro. Neste endereço foi fundada a primeira "escola para crianças pequenas" do Brasil. O investimento, de iniciativa privada, foi realizado pelo médico Joaquim José de Menezes Vieira e de sua esposa Carlota de Menezes Vieira, que objetivavam colocar em prática as orientações pedagógicas dos educadores Froebel e Pestalozzi para meninos de 3 a 6 anos de idade, iniciados em atividades como ginástica, pintura, desenho, exercícios de linguagem, cálculo, leitura e escrita.

No ano de 1896, o governo de Bernardino de Campos inaugurou o jardim de infância modelo de São Paulo. O estabelecimento funcionou como anexo à antiga Escola Normal do Estado Caetano de Campos, situado à praça da República. O jardim de infância foi o pioneiro como escola de aplicação, funcionando como campo de experimentação de novos materiais didáticos e inusitadas práticas pedagógicas, orientados pelo método intuitivo, sob a lógica da lição de coisas e do estudo do meio.

Comumente, os jardins de infância eram criados sob a tutela das escolas normais, porque se constituíram laboratório para os estudos pedagógicos, lições de puericultura e práticas de ensino. O programa de formação para o magistério exigia das normalistas a vivência do estágio docente, com a realização de experiências didáticas em espaços reais de atuação. Tratava-se do cultivo da dimensão prática do curso em diálogo com os fundamentos teóricos da educação, por se compreender que lidavam com uma ciência aplicada. 


\section{PRÁTICAS ESCOLARES NO INTERIOR DO JARDIM DE INFÂNCIA MODELO DE NATAL- RN}

O Jardim de Infância Modelo de Natal foi fundado em 1953 pelo governador Sylvio Pedroza, atendendo ao ideário escolanovista, sob a orientações das prerrogativas do professor Anísio Teixeira. Na cidade de Natal, RN, o prédio imponente foi construído próximo à Praça Pedro Velho, no bairro de Petrópolis, precisamente na esquina da Avenida Prudente de Morais com a Rua Trairi, número 400. Espaço urbano que se tornou nobre pela construção de edificações modernas em terrenos planos e amplos, garantido a expansão da cidade no período pós-Segunda Guerra Mundial. Segundo Mendes (2015, p. 113)

A arquitetura do Jardim de Infância Modelo configurava-se no protomodernismo com influência de Le Corbusier. As fachadas simplificam-se, eliminando formas rebuscadas. Os beirais e os ornamentos se restringiam a pequenos frontões, marcando a entrada da escola. Outro aspecto marcante de sua estrutura seria os arcos plenos semelhantes às edificações religiosas, neocolonial. O edifício simplifica-se, sem ornamentos, devido também à necessidade de economia financeira aliada à facilidade construtiva.

A sociedade natalense dispunha enfim de um prédio específico para abrigar o Jardim de Infância, que peregrinou nas dependências anexas ao Atheneu Rio-Grandense e ao Grupo Escolar Augusto Severo. O jardim de infância modelo integrava o Instituto de Educação, complexo pensado para a formação de professores que atuariam na escola primária. A princípio, estaria situado dentro do prédio em forma de " $x$ ", localizado na Rua Campos Sales, construído para abrigar o Instituto de Educação, mas por questões políticas foi deslocado para prédio localizado na Praça Pedro Velho.

A estrutura continha cinco salas de aula rodeada por alpendres, banheiros feminino e masculino, espaços destinados ao centro clínico, salão coberto e pátio para recreação. A edificação, conforme prescrições higienistas, continha ambiente amplos, contando com bastante ventilação e iluminação. A figura 1 explicita a planta baixa, como era a disposição do espaço físico da instituição:

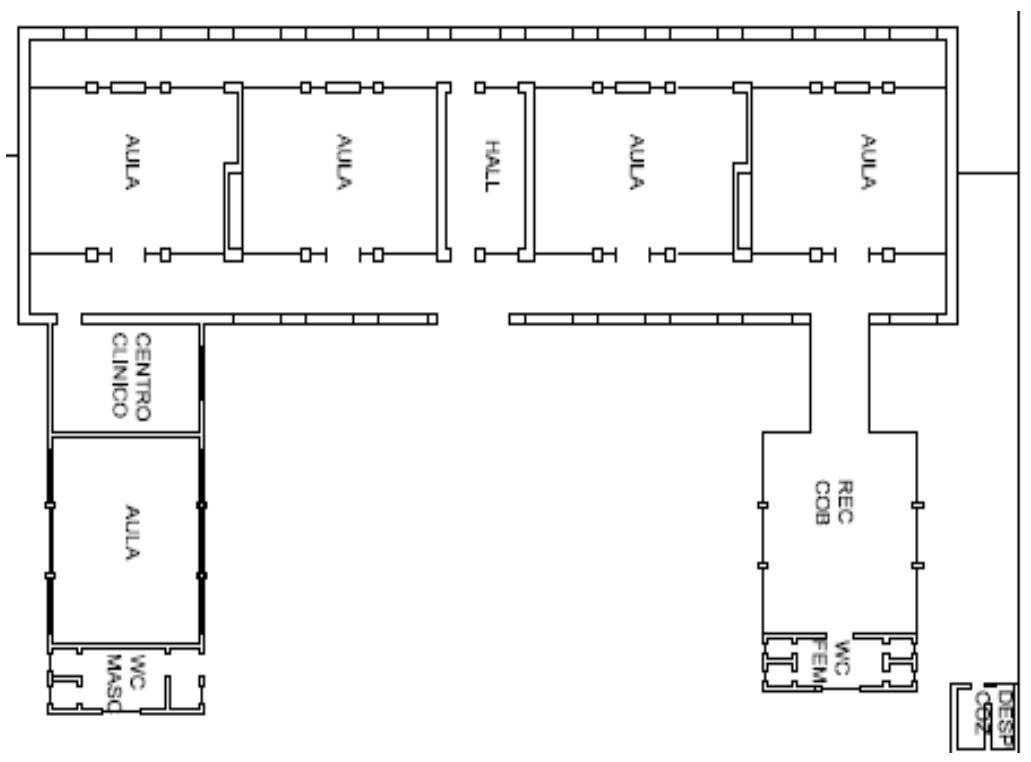

Figura 1: Planta baixa do Jardim de Infância Modelo - Natal, RN

(Fonte: SMCE/SEEC/RN) 
O dia da inauguração foi uma data memorável, pois "[...] o Jardim de Infância Modelo era algo esperado pela sociedade natalense. No grande dia, havia a presença de políticos, familiares, imprensa, alunos, professores, todos ansiosos com esse novo espaço educacional." (MENDES, 2015 , p. 110). A escola para a infância apresentou-se como mais um bem público de projeção social, política e pedagógica na cidade do Natal. A instalação de uma instituição de ensino dessa natureza concretizava os princípios da escola nova, que defendia uma escola pública e laica, bandeira esta alçada pelo estado republicano.

A criação da instituição somente foi possível diante de um acordo firmado entre Ministério da Educação e Saúde (MES) e o Instituto Nacional de Estudos e Pesquisas (INEP) com o Governo do Estado, garantindo auxílio para a compra de equipamentos e aparelhagem pedagógica. Para Mendes $(2015$, p. 109) "[...] a escola criada na modernidade, estava vinculada a um projeto político fundamentado num ideal de 'ordem e progresso', na qual se visava alfabetizar os cidadãos para assumirem condutas morais e cívicas produzidas pela cultura nacional."

Desse modo, o Jardim de Infância Modelo foi criado com a intenção definida: abrigar um tipo de infância que se pretendia formar para o modelo de sociedade dos anos 1960 e 1970. Tratava-se de uma geração de pequeninos selecionados socialmente para viver uma rotina responsável por inculcar determinados conceitos, valores e comportamentos. Para tanto, foi planejado um espaço físico, que dispunha de uma lógica para o adestramento dos corpos e o disciplinamento das almas.

A seguir, na Figura 2, podemos observar a imponente arquitetura da fachada do prédio, que ostentava estrutura em grandes arcos, com finalidade de sustentar o alpendre frontal da edificação. Notemos o equilíbrio na simetria pela disposição de seis arcos em cada lado e a disposição de um portal central, lugar por onde as crianças, familiares e professores tinhas acesso a instituição.

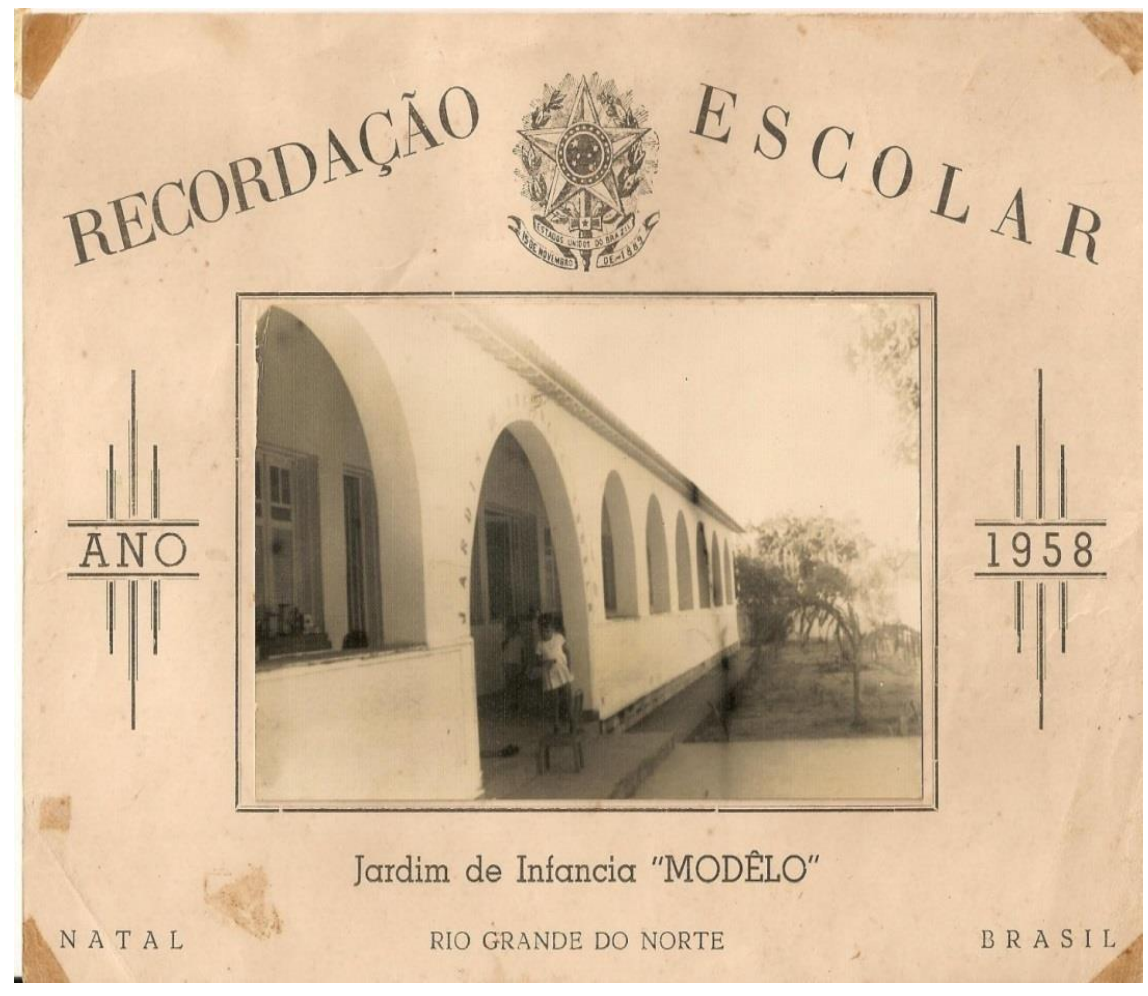

Figura 2: Fachada do Jardim de Infância Modelo de Natal - RN (Fonte: Arquivo do IESP) 
No interior desse Jardim de Infância Modelo de Natal, foram instituídas práticas escolares de três natureza: as relacionadas ao desenvolvimento cognitivo; as de cunho de formação moral e cívica; e, as que contribuíam com o desenvolvimento físico. A instituição estabelecia uma cultura escolar que visava atingir as dimensões do intelecto, da cultura e do corpo de cada criança, o que Mendes (2015, p. 130) identificou como "tripé da educação republicana: intelecto, moral e físico".

A instituição de práticas escolares direcionadas para o desenvolvimento do intelecto estava vinculada a concepção de que a escola de educação infantil funcionaria como período preparatório para a criança se tornar aluno(a) do ensino primário. A ideia de pré-escola muda a essência da cultura escolar, associando práticas de cuidar às práticas de educar. Educar no sentido de pensar sobre conceitos essenciais para a iniciação na trajetória escolar obrigatória. Nesse contexto, ocorreu a necessidade da elaboração de um currículo catalizador de saberes, adquiridos pela experiência pessoal, contato com materiais concretos e interação com o meio ambiente.

O intento da formação cognitiva se materializou nas atividades práticas promovidas nas oficinas de artes e trabalhos manuais; aulas de alfabetização e de raciocínio lógico; aulas de campo para interagir com elementos da natureza. Por meio dessas atividades, as professoras objetivavam o desenvolvimento do pensamento e a construção de conceitos pelos alunos que frequentavam o Jardim de Infância. A ênfase estava na vivência do método ativo de conhecimento, que propunha a interação com materiais concretos e o meio ambiente, fosse sociocultural ou natural.

Na figura 3, podemos observar o desenvolvimento de uma aula de educação artística numa sala mista, onde as crianças são dispostas em mobiliário adaptados à faixa etária delas. Observamos a presença de mesas em forma de arco que dispõe as crianças em círculo, oportunizando uma atividade de partilha, colocando em prática a proposta do trabalho de grupo, cultivando valores para a coletividade e as sociabilidades.

O espaço denuncia a materialização dos pressupostos da escola ativa pelo desenvolvimento de uma atividade manual, pela experimentação de materiais didáticos que motivam as crianças pela interação com pranchas de pincéis, tintas, telas e dobraduras. Atividades que possibilitam a criatividade e o raciocínio lógico, supervisionadas por adultos que coordenam e orientam, mediante a necessidade de aprendizagem de cada aluno. No caso da sala de aula em evidência, há a presença de educadora que se dispõem a estar junto de seus alunos.

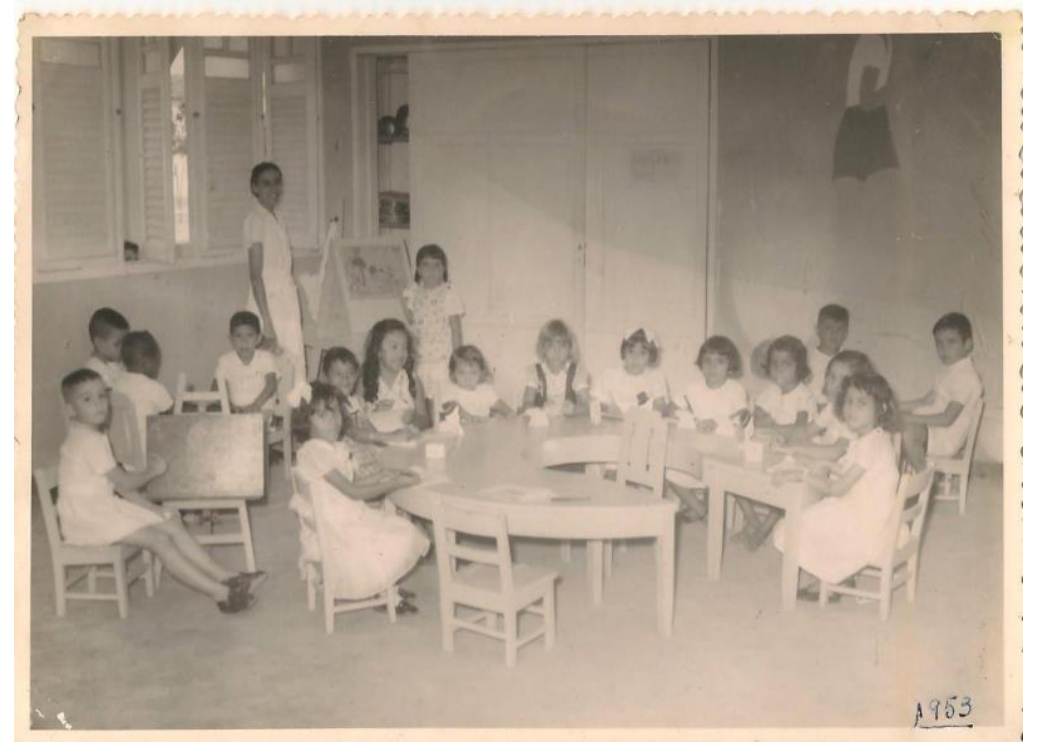

Figura 3: Atividade em sala de aula, 1953

(Fonte: Arquivo do IESP) 
Comumente as atividades que motivavam o intelecto eram realizadas no interior das salas de aula, com as crianças sentadas e cobradas ao silêncio e a concentração. Mesmo sendo convidadas à experimentação, eram subjugadas a ritos e modelos a serem seguidos. O que prova, que apesar da presença do método ativo, a rotina impunha uma disciplina que iniciava-se no ordenamento da disposição dos corpos nos espaços físicos das salas de aulas, corredores, pátios e varandas.

O Jardim de Infância Modelo de Natal ainda se propunha a contribuir para o desenvolvimento do caráter da criança, pelo cultivo dos valores, dos bons costumes e atitudes de civilidade. A instituição de práticas escolares direcionadas para o desenvolvimento da moral atrelava-se ao desenvolvimento de atividades religiosas como a exemplo do "batismo das bonecas" realizado por um pároco que vinha celebrar e ungia os brinquedos das crianças; atividades cívicas de comemoração pela da semana da pátria, com fardamento, desfile, hinos patrióticos e honras aos símbolos nacionais.

Na Figura 4, vemos a realização de uma cerimônia religiosa bem atípica, porque trata-se de um "batismo de bonecas" realizado por um pároco que, anualmente, participava da semana da criança. A festividade demonstra o quanto a religiosidade apresenta-se como elemento formador e o ato de benção dos brinquedos dissemina os valores cristãos para a vida social das crianças do Jardim de Infância Modelo de Natal. Na foto, observamos a presença da comunidade, sob o testemunho e aprovação dos familiares, presença das genitoras, em pé, em segundo plano.

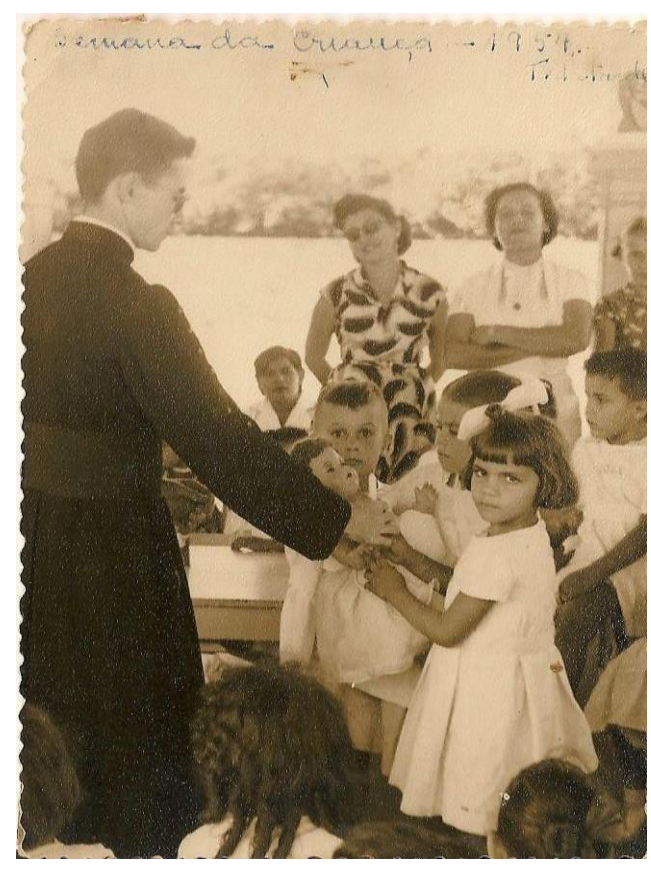

Figura 4: Batismo de Bonecas na semana da criança, 1954.

(Fonte: Arquivo do IESP)

Observamos a presença da igreja no interior da instituição pela presença do ministro da fé, realizando uma ação subjetiva: abençoando os brinquedos que as crianças recebiam na semana da criança. Tratava-se de festividade anual, que era realizada durante o mês de outubro e que congregava todas as classes da escola e familiares em torno de solenidades e brincadeiras. Oportunidade para o cultivo das representações sociais do ser "criança feliz" numa sociedade repleta de contradições.

Outro evento que imputava de forma marcante os valores morais era o desfile da pátria, realizado no mês de setembro. Momento em que os alunos do Jardim de Infância Modelo 
passeavam fardados pelas principais ruas do bairro da Ribeira, representando a instituição. $O$ conclave tinha maior repercussão que a semana da criança, pois apresentava visibilidade social para a comunidade, tinha por objetivo iniciar os infantes no culto aos símbolos patrióticos e a reverência à pátria.

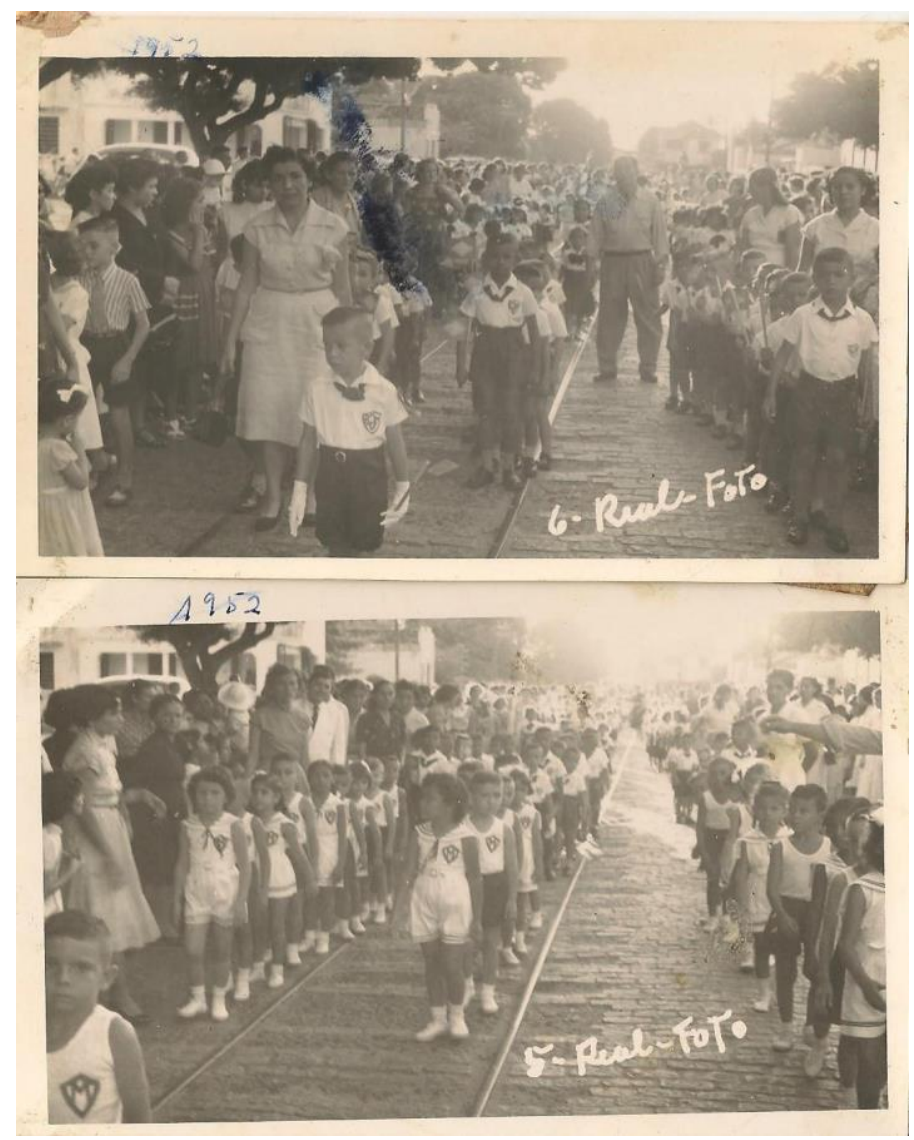

Figura 5: Desfile Cívico, 1952.

(Fonte: Arquivo do IESP)

$\mathrm{Na}$ fotografia, notamos que os valores patrióticos extrapolavam o discurso e se materializavam nas práticas quando os familiares e a instituição se esforçavam para que as crianças estivessem todas uniformizadas, ordenadas em fileiras para desfilarem diante dos olhos da sociedade natalense. Para Mendes (2015, p. 141) "[...] essa festividade cria um sentido de corporificação, onde os gestos, as vestes e movimentos se constituem elementos valiosos para a formação de valores."

Havia uma disposição da ordem pelos corpos enfileirados e dispostos a obedecer um cerimonial público e de reconhecimento social. Ocorria durante o evento uma legitimação da ação educativa, considerada essencial para a formação dos participantes, inclusive das crianças pequenas.

O Jardim de Infância Modelo também dedicava tempo em seu currículo para as práticas escolares direcionadas para o desenvolvimento físico da criança, quando eram organizados momentos recreativos e atividades de esporte que motivavam a criatividade, a diversão e a competição. Mesmo sendo orientadas pelos adultos, as crianças se sentiam livres, como observamos no jogo de força denominado de "Cabo de Guerra" explicitado na foto a seguir. 


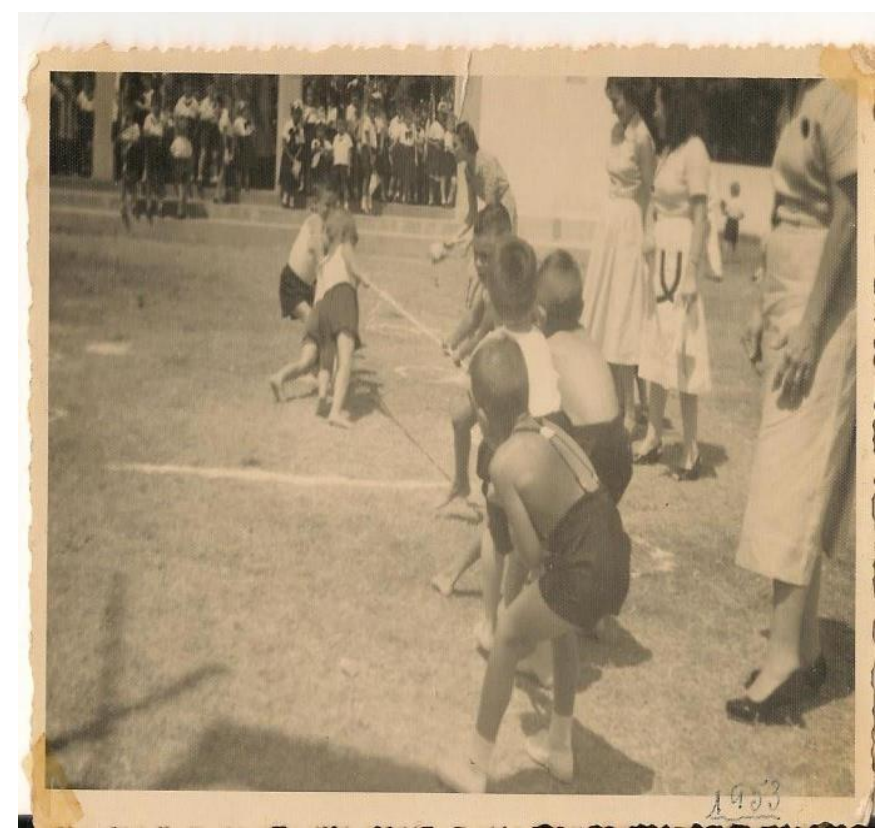

Figura 6: Aula de educação física, 1953.

(Fonte: Arquivo do IESP)

Era comum as educadoras envolverem as crianças em atividades de competição, porque exigiam das crianças bastante energia. Elas gostavam de participar desses eventos porque requeria delas muito movimento e disposição para resolver os desafios. As gincanas, como eram conhecidas, envolviam brincadeiras previamente planejadas. Cada qual tinha o seu objetivo, conforme os fundamentos da pedagogia: toda a ação tem o seu propósito, sua finalidade.

Segundo Foucault (1987), no âmbito da sociedade moderna há uma disposição para o controle dos corpos pela exigência da disciplina por meio de mecanismo de controle, que se circunscrevem desde a divisão do tempo, organização do cotidiano, arquitetura dos espaços e disposição dos movimentos dos sujeitos numa dada realidade.

Investir no desenvolvimento físico das crianças completava a máxima de que elas necessitavam de mente e corpo saudáveis. Temos, então, nuances de uma proposição de educação integral dos sujeitos? Temos a disposição novas concepções de fazer educação infantil, baseada na certeza de que as crianças pequenas também pensam, necessitam de saúde e são importantes para o desenvolvimento da sociedade moderna. As culturas infantis, que se instituía cultura escolar, eram desenvolvidas no pátio do recreio e promoviam uma sólida formação de caráter por meio do disciplinamento dos corpos das crianças de forma consciente e intencionada. (JULIA, 2001)

\section{CONSIDERAÇÕES FINAIS}

Em suma, a história do Jardim de Infância Modelo de Natal foi constituída por três fases: a primeira fase que compreendeu a criação e regulamentação da instituição de ensino e campo de aplicação da Escola Normal que vai desde 1908, ano de construção do Grupo Escolar Augusto Severo, até 1953, momento em que ocorreu a edificação do prédio no bairro de Petrópolis; a segunda fase marca o pleno funcionamento da instituição durante os anos de 1954 até 1965; e, a terceira fase, de 1965 até 1971, momento em que ocorreu a mudança do Jardim para outro prédio, situado no Instituto de Educação Presidente Kennedy, construído no bairro de Lagoa Nova. 
A trajetória histórica dessa instituição de educação se confunde com a existência da Escola Normal de Natal, pelo fato de servir, por décadas, como campo de aplicação das teorias da didática estudada pelas normalistas. O Jardim de Infância Modelo pode ser considerado cenário privilegiado em que ocorreu a consolidação científica dos pressupostos pedagógicos da escola nova no Rio Grande do Norte, durante os primeiros decênios do Século XX.

A instituição de prestigiada memória na história da educação infantil de Natal forneceu importante contribuição para a organização de uma cultura escolar para os jardins de infância na cidade. Sob os preceitos do método intuitivo, a instituição inovou nas práticas de ensino pautadas na experimentação e criatividade, mas, também, não descuidou da postura conservadora, reflexo da sociedade da época, quando investiu em atividades de controle e disciplinamento pelo cultivo da moral e do civismo.

Nesta oportunidade, notamos que o estabelecimento de ensino em foco estabeleceu uma cultura escolar para educação infantil a partir da vivência de práticas que visavam o desenvolvimento cognitivo; o cultivo de valores pela moral e o civismo; e, a participação em eventos desportivos e de educação física. Desse modo, no âmbito do jardim de infância havia uma preocupação com o físico, a mente e a moral da criança pequena, ideário próprio de educação integral, que torna-se anseio no ventre de uma sociedade que se diz moderna.

\section{REFERÊNCIAS}

1. BRASIL. Decreto-lei $n^{\circ} 8.530$, de 2 de janeiro de 1946. Lei Orgânica do Ensino Normal.

2. CARDOSO FILHO, R. O primeiro jardim de infância do Brasil (1862): um lugar de memória? Disponível em: <http://www2.faced.ufu.br/colubhe06/anais/arquivos/151RonieCardosoFilho .pdf> Acesso em: 17 jun. 2016.

3. CERTEAU, M. de. A escrita da história. Rio de Janeiro: Forense Universitária, 1982.

4. FOUCAULT, M. Vigiar e Punir: nascimento da prisão. Petrópolis: Vozes, 1987.

5. JULIA, D. A cultura escolar como objeto histórico. In: Revista Brasileira de História da Educação. no 1, jan./jun., 2001.

6. KUHLMANN JUNIOR, Moysés. História da educação infantil brasileira. Revista Brasileira de Educação. n. 14, maio/ago., 2000. Disponível em: http://www.scielo.br/pdf/rbedu/n14/n14a 02 Acesso em: 15 jul. 2016.

7. LE GOFF, J. História e memória. Campinas, SP: Editora Unicamp, 1994.

8. MARTINS, A. M. de S. Os anos dourados e a formação do professor primário no Instituto de Educação do Rio de Janeiro (1945-1960). Revista Teias, v. 1, n. 1, 15 p., 2000. Disponível em: <http://www.periodicos.proped.pro.br/index.php/revistateias/article/viewFile/18/20> Acesso em: 14 jun. 2016.

9. MENDES, S. de L. O modelo de educação do jardim de infância natalense (1916-1953). Natal, 2015. Dissertação de Mestrado - Centro de Educação - Universidade Federal do Rio Grande do Norte, 2015, $171 \mathrm{f}$. 